AC 2012-3112: WHY DO PROFESSIONALS RETURN TO SCHOOL FOR GRADUATE DEGREES?

Dr. Diane L. Peters P.E., LMS International

Diane Peters received her Ph.D. from the University of Michigan in 2010. In addition to a position as a Senior Control Systems Engineer at LMS International, she conducts engineering education research on returning students with collaborators at the University of Michigan.

Dr. Shanna R. Daly, University of Michigan

(C)American Society for Engineering Education, 2012 


\section{Why Do Professionals Return to School for Graduate Degrees?}

Recently, there has been increased interest in the population of graduate students who have worked for significant amounts of time prior to their graduate studies. These "returning students" have a diverse range of experiences between their undergraduate and graduate careers, and have different reasons why their pathways lead to graduate school.

To study these pathways, we interviewed ten graduate students at a major Midwestern university who had at least five years' gap between the completion of their undergraduate degree and the start of their current graduate degree. The participants came from different academic departments and included both masters' and doctoral students of various ages and statuses in their programs. Three reasons why participants returned to school emerged from data analysis:

$>$ To transition from their current career path into an academic career path;

$>$ To change the focus of their industrial career into a new specialty area;

$>$ To advance further along their current career path.

In this paper, we discuss these categories and the students who chose those paths. We also address the implications for graduate schools regarding the recruitment and support of returning students.

\section{Introduction}

Returners are those with undergraduate degrees who work outside of academia for at least five years and come back to the academic setting to earn a graduate degree. However, little research exists on this group, and in STEM fields especially, to shed light on the reasons why they make the decision to return. Understanding the reasons for their decisions to return is important, as returners have a unique perspective that can result in distinct work from direct-pathway students, defined as those who go to graduate school promptly after completing their undergraduate degree. Returners have real-world experiences as practitioners, and these experiences influence their research during graduate school and their post-graduate school choices ${ }^{1,2,3}$. While returners are in a position to make unique contributions to their fields, little research exists to understand the reasons why they choose to return to graduate school.

\section{Background}

Very little research has been conducted on engineering returners, although there is some scholarship on older students in general. Most of this research focuses on the characteristics of older students, with some work on their experiences. The motivations of engineering returners have not been studied, nor are there any studies showing how large this population is. Local data from the University of Michigan showed that, out of approximately 1000 engineering $\mathrm{PhD}$ students, 170 had at least five years between their undergraduate and $\mathrm{PhD}$ programs ${ }^{4}$.

Research on the engineering returner population revealed that returners face challenges in both admission and persistence in graduate programs. Some programs are less welcoming to returners through their recruitment, admissions criteria, and overall structure, and if admitted, returners 
struggle to finance their education, fit in to the graduate population, and balance school with their personal lives ${ }^{5}$. Another study examined engineering practitioners who chose to pursue a doctorate in engineering education ${ }^{6}$. Researchers discovered that returners experienced frustrations because they felt their past experiences were not valued and that their professors were not interested in their industry experiences and related skills and knowledge.

In our earlier work on the experiences of returners once in graduate school, we found that returners did not doubt their ability to succeed in graduate school, but instead, made the decision to persist based on the ability to balance the costs of the experience ${ }^{7,8}$. Costs included those related to intellectual challenges, finances, balancing graduate school with family and community responsibilities, adapting to the culture of graduate school life, and maintaining their self-confidence. In the study, returners revealed strategies they used to reduce and mitigate these costs. The perception of costs related to returning is one factor that affects practitioners' decisions to return. However, other contributions to the decision to return is limited in the literature.

While we found no studies of reasons practitioners in engineering and the sciences return, some work does exist on returners in non-STEM fields and on the motivations of traditional graduate students in STEM fields. Stoecker ${ }^{9}$ studied professionals in the field of physical therapy who returned to graduate school in order to determine the factors that led them to return. This study examined both intrinsic and extrinsic influences on the decision to return, with the most important extrinsic detractor related to the financial cost of the program. Among the intrinsic factors, the largest influence was the desire to advance in professional skills, followed by the desire to specialize and increase income.

In the literature specifically focusing on the STEM fields, one study by Crede and Borrego ${ }^{10}$ examined the perceptions of graduate school held by undergraduate engineering students and their decisions to enroll. In that study, the top reasons to attend graduate school were to learn more and to have an advanced degree, followed by the desire to earn a higher salary. Other reasons including learning how to do research, the requirement of a graduate degree for a specific career, as a backup in case the student was unable to find a job, and to switch from one area of study to another. Since this study was conducted specifically on undergraduates, it provides a useful perspective on the motivations of direct-pathway students; however, it does not provide information on returners and their motivations. Similarly, a study by Perna ${ }^{11}$ aimed to understand the impact of sex and racial/ethnic identity on graduate school enrollment by studying the decisions made by undergraduate students. They showed that, while women and minorities have lower rates of enrollment in graduate school than do men who are not racial or ethnic minorities, their enrollment could be increased through programs that courted women and minorities within the undergraduate population. However, this also does not provide any insight into returners' decisions to enroll in graduate programs.

Another study, conducted by Anderson and Swazey ${ }^{12}$, studied enrolled graduate students and thus captured a population that contained both direct-pathway students and returners. This study aimed to attribute weights to different reasons that graduate students in STEM fields chose to earn attend graduate school. Graduate students were surveyed on how important ten different motivations were for their graduate school attendance. These motivations were the desire for 
knowledge in the field; desire to do research in the field; desire to teach in higher education; desire to benefit others through this work; desire to advance in current employment; desire for a job that pays well; the lifestyle of a scientist; the high regard in which scientists are held; desire to change careers; and the inability to think of anything better to do. All ten of those motivations were rated as "very" or "somewhat" important by significant numbers of respondents. As the categories of reasons were pre-defined for study participants, it is unclear if other, perhaps more important, reasons existed in the decision to return. As the study was aimed at the graduate student body as a whole, this study does not shed light on the specific motivations of returners, although they were included in the study population.

Schilling ${ }^{5}$ claimed that graduate students with industry experience often desire to teach; however, no data were presented in this work, and other reasons why practitioners return were not discussed. Practitioners transitioning into academic careers are also addressed in Fairweather $\&$ Paulson ${ }^{13}$, as they examined the role that industrial experience plays in a faculty member's commitment to teaching. In that study, they found that industrial experience had a significant positive impact on faculty members' commitment to teaching; however, other reasons why practitioners might choose to pursue a graduate degree were not addressed, as they were outside the scope of that work.

Motivation for graduate school is of some concern in the body of work on how to encourage students to consider graduate school, e.g., Anderson-Rowland ${ }^{14}$; however, the primary focus of that work is on why students might choose not to pursue graduate study and how to overcome those objections, and the students of interest are engineering undergraduates, not engineering practitioners. This body of work, therefore, does not address the question of why practitioners may choose to return to graduate school, though it can be useful to understand the motivations of their direct-pathway counterparts.

\section{Research Design}

\section{A. Research Questions}

Our work was guided by the research question, "Why do professionals choose to return to school for a graduate degree?"

\section{B. Participants}

In this study, we collected data from ten returners, all from a single, major Midwestern research university. While our focus was on returners in engineering, we also included participants from other STEM fields, with the expectation that their motivations and experiences would be comparable to engineering returners. Recruitment was conducted using the researchers' networking channels, and was designed to ensure that a diverse group of returners would be included in the study. The participants were split approximately equally between males and females and were varied in age, work experience, stage of graduate career, and length of time as a practitioner (which we refer to as 'gap years'). Key demographic data for the participants is given in Table 1. 
Table 1. Demographic Data for Study Participants

\begin{tabular}{|c|c|c|c|c|c|}
\hline Pseudonym & Gender & Age & Gap Years & Current Status & $\begin{array}{l}\text { Graduate Field } \\
\text { of Study }\end{array}$ \\
\hline Andrew & Male & 33 & 7 & $\begin{array}{c}\text { Third year } \mathrm{PhD} \\
\text { student }\end{array}$ & $\begin{array}{l}\text { Mechanical } \\
\text { Engineering }\end{array}$ \\
\hline Brenda & Female & 38 & 5 & $\begin{array}{l}\text { Post-doctoral } \\
\text { Researcher }\end{array}$ & $\begin{array}{c}\text { Applied Physics } \\
\text { \& Engineering }\end{array}$ \\
\hline Catherine & Female & 41 & 18 & $\begin{array}{l}\text { First year PhD } \\
\text { student }\end{array}$ & Design \\
\hline Danielle & Female & 45 & 15 & $\begin{array}{l}\text { Recently finished } \\
\mathrm{PhD}\end{array}$ & $\begin{array}{c}\text { Electrical } \\
\text { Engineering }\end{array}$ \\
\hline Evan & Male & 29 & 5 & $\begin{array}{l}\text { Second year } \mathrm{PhD} \\
\text { student }\end{array}$ & $\begin{array}{l}\text { Mechanical } \\
\text { Engineering }\end{array}$ \\
\hline Felicia & Female & 30 & 6 & $\begin{array}{c}\text { Third year Masters' } \\
\text { student }\end{array}$ & $\begin{array}{c}\text { Biomedical } \\
\text { Engineering }\end{array}$ \\
\hline Gary & Male & 27 & 5 & $\begin{array}{c}\text { First year Masters' } \\
\text { student }\end{array}$ & $\begin{array}{l}\text { Computer } \\
\text { Engineering }\end{array}$ \\
\hline Harald & Male & 26 & 5 & $\begin{array}{l}\text { First year PhD } \\
\text { student }\end{array}$ & Chemistry \\
\hline Ian & Male & 30 & 8 & $\begin{array}{c}\begin{array}{c}\text { First year Masters' } \\
\text { student }\end{array} \\
\end{array}$ & $\begin{array}{l}\text { Aerospace } \\
\text { Engineering }\end{array}$ \\
\hline John & Male & 28 & 6 & $\begin{array}{l}\text { First year } \mathrm{PhD} \\
\text { student }\end{array}$ & $\begin{array}{l}\text { Mechanical } \\
\text { Engineering }\end{array}$ \\
\hline
\end{tabular}

\section{Data Collection}

Data were collected using semi-structured interviews. The interview included questions about participants' decisions to return as well as the returning experience, but for the purpose of this paper, our focus was on the decision to return. We asked participants to take us through their decision process as if they were telling it as a story. We followed up with specific questions about their goals for returning, how they chose a program, and what advice they would have for others considering returning. Interviews lasted approximately one hour, with about one-third of the interviews focused on the decision of returning. They were audio recorded, and a transcript was produced after the completion of each interview.

\section{Results}

Our results showed that the participants in our study all had definite reasons why they were returning to school, but the reasons differed from one participant to the next. These reasons fell into three main categories. These categories, as well as the participants whose experiences are represented in each category, are given in Table 2, below. 
Table 2: Participant Reasons to Return to School

\begin{tabular}{|l|l|}
\hline Reason for Returning & Participants \\
\hline \multirow{4}{*}{$\begin{array}{l}\text { To transition from an industry career } \\
\text { pathway to an academic career pathway }\end{array}$} & Brenda \\
\cline { 2 - 2 } & Evan \\
\cline { 2 - 2 } & Gary \\
\cline { 2 - 2 } & Ian \\
\cline { 2 - 2 } $\begin{array}{l}\text { To change the focus or direction of an } \\
\text { industrial career into a new specialty area }\end{array}$ & Andrew \\
\cline { 2 - 2 } To advance in a current career path & Felicia \\
\hline \multirow{2}{*}{ Catherine } \\
\cline { 2 - 2 } & Danielle \\
\cline { 2 - 2 } & Harald \\
\hline
\end{tabular}

\section{Transition to an Academic Pathway}

Half of our participants, five out of the ten, expressed that their motivation for pursuing a graduate degree was the desire to transition into an academic career. The types of academic career paths they wished to pursue varied somewhat, with some participants focused more on teaching and others aiming at research institutions.

Brenda initially decided to pursue an academic career because of a desire to teach, but while in graduate school she became more interested in research. As she discussed her decision to return to school, she started out by discussing teaching.

I was teaching in inner-city New York, and I wanted to continue teaching... I wanted to be able to go back and actually teach at $<$ College $>$... so for me it didn't matter what my research area was in.

Although she initially had no strong opinions on her research area, she later became very interested in her research; because of her funding source, she had flexibility in choosing a research area, and she came to regard it as a significant part of her academic identity.

[I]t's really important stuff... So those were all positive experiences, you know, I had the freedom to make my $\mathrm{PhD}$ be anything I wanted.

Because of her dual interest in teaching and research, she decided to pursue her future academic career at a university that placed a significant emphasis on research as well as teaching.

Evan was less specific about what type of institution where he wanted to work after completing his doctorate, but he did express an interest in teaching as the reason for wishing to pursue an academic career.

I was interested in eventually getting my $\mathrm{PhD}$ and teaching... my ultimate goal is to... stay in academia... and teach. 
Like Brenda, he was interested in his research area; however, he knew his research interests when he started the program, rather than developing an interest over the course of the work, and specifically chose an advisor based on those interests.

[B]efore I even came in I was researching professors and I e-mailed her and, and said I was hoping that I'd have a chance to, to meet with her when I came to campus and we met when I was at campus and she was, with all the professors that I met, it was, she was still the one that was doing things that were the most interesting and I thought I'd really enjoy working for her... I thought it over and maybe a week after I came and did the campus visit I e-mailed her again and said that I liked the tour and if she had a position in her lab... I would like to be a part of her lab and she said she did.

Unlike Brenda and Evan, Gary displayed relatively little interest in research, and his interest in an academic career was focused almost exclusively on teaching.

I would like to teach college... I have always wanted to do that. Research is OK. I have certain critiques of it. I'm willing to put in my dues... to teach.

Ian also was focused on the teaching aspect of academia, but his situation was unique in that his transition to academia was not intended to be permanent. As an active-duty member of the military, he was to be assigned to teach for two years at a military academy following his graduate degree, followed by a return to active service in a non-academic setting. Like the other participant, he had a definite interest in teaching, and was determined to learn what he needed to do it well.

[M]y motivation is to understand, because I'm going to be teaching it... It's cool, because I'm learning a ton, and I think it's going to make me more well-rounded, and a better instructor.

John also came back with a strong interest in teaching, but also discussed an interest in research.

I wanted to have more freedom to do research, to investigate stuff, and so I came back. And I love to teach. So that's why I came back, to become a university professor is my goal.

However, unlike Evan, he came back to school without a particular research area that he wanted to pursue, though he did quickly choose an area in which to focus. In his case, the lack of specificity in his research interest was due primarily to having a diverse range of interests.

I can apply my skills to very different areas. And so... in some ways I actually went with the broadest, I went design and manufacturing. And it's something similar to what I've been doing and I could apply some of my skills. As an undergrad, I was actually a fluids/mechanics/thermodynamics person. I was very good at that, very interested in doing that and in continuing that stuff. 
These participants were driven to return because they wanted to transition into an academic career path, thus a graduate degree was the necessary step to make that transition. While this was the motivation of five of our participants, the other five participants were driven by different career-related reasons.

\section{Changing Focus of an Industrial Career}

Two participants, Andrew and Felicia, wanted to return to an industrial career after their graduate degree, but with a different focus. Andrew, who was pursuing a doctorate, expressed an interest in changing his research area within his existing field of mechanical engineering.

Now at the time I decided to come back, part of the reason was that I was in R\&D and it had been pointed out to me that getting a $\mathrm{PhD}$ would be more useful as far as mobility within an R\&D environment... to make sort of a sideways move in R\&D can be difficult if you don't have experience in a given area, and so I had an idea of the kind of research I wanted to do and so I figured if I could go back to school and do that research that would be a way to get into that area.

Felicia was pursuing a change both in her career direction and also in her field within engineering; her undergraduate degree was mechanical engineering, but she was pursuing a masters' degree in biomedical engineering.

[T]he biggest thing for the masters' degree was, you know, I worked in automotive for six years. Trying to switch industries, I felt like it would be more forgivable if I had... a masters' degree focusing on... biomechanical, bio, you know, medical type stuff, that it would be easier to shift over as opposed to just saying, hey, I worked in automotive for six years, and now I want to jump...

In her case, the masters' degree would provide what she needed to accomplish her goals, and therefore she was not planning to pursue a doctorate.

In these two cases, earning a graduate degree provided a stepping-stone to advancing as a practitioner of the field. These two participants wanted to remain in industry, but felt a graduate degree was necessary to transition to a new area of work.

\section{Advancing in Current Career Pathway}

Three participants, Catherine, Danielle, and Harald, chose to return for a graduate degree in order to advance along their current career pathway. In Catherine's case, she was able to do so with funding from her current employer, a government research organization, with the knowledge that her existing job would be waiting for her when she finished her degree. Her primary focus in pursuing a doctoral degree was the knowledge gained, and how she could bring it back to her organization and put it to use.

I wanted to bring something to aerospace that I did not believe there was sufficient expertise in... my goal is to grow as a human being, to become more knowledgeable and 
to bring that knowledge back to <employer> and to the aerospace community overall, and to improve the planet earth.

In contrast, while Danielle took a leave of absence and planned to return to her current employer, the impact of the credential was the primary way in which her career would be enhanced by a doctorate. She was working on research projects that interested her prior to beginning her doctorate, but without the degree, she was unable to be the Principal Investigator (PI) on her projects.

Now what I find is that unless I have a PhD you cannot own your own funding, no matter how many papers you've written... So you have to have a $\mathrm{PhD}$

By getting a doctorate, she would be able be a PI on her projects, define their direction, and exert a greater degree of control.

Harald, unlike Catherine and Danielle, chose to leave his employer to pursue his doctorate, and did not anticipate going back to that employer, though he was remaining in the same specialty. He felt that his previous employer would not provide the opportunities that he wanted.

Well, the job I was working... was sort of a - I don't want to say dead end, because it's not really - it was fulfilling and everything but it was kind of at the top of the ladder and I wanted to move beyond that, so a graduate degree was pretty much... my view was the way to do that.

While these three participants were practitioners in different types of organizations (government, academic, and industry), they saw the $\mathrm{PhD}$ as a way to advance their careers in the type of work they were already doing. While this advancement could lead to greater pay, the financial aspect of career advancement was not expressed as a motivation. Rather, they saw career advancement in terms of the type of work they were able to do, and in what degree of control they would have over their choice of projects and how those projects were carried out.

\section{Discussion}

In our in-depth analysis of this sample of returners, three categories of motivation for returning to school emerged from the data. This contrasts with the ten motivations Anderson and Swazey ${ }^{12}$ used in the survey of graduate students in engineering and science. Here, we briefly discuss the relation of our findings to that work, and in particular to each of those motivations, and explain why several of those motivations did not appear in our study. These motivations are discussed in the order of importance found by Anderson and Swazey.

\section{Desire for knowledge in this field}

Our participants had a strong interest in their academic field, and were all passionate about it; however, this was not a major motivation in returning to school. Catherine came closest to this motivation, in her statement that she wanted "to learn something new, to expand my horizons"; however, this was not a primary motivation to return, since she was able to gain new knowledge without a doctorate. She stated that "where I was working... you can do some amazing research 
without a doctorate." Similarly, other participants indicated that they had opportunities to learn and gain knowledge in the working environment.

Desire to do research in this field

In our study, participants' interest level in research varied, with some showing a very strong interest in research. However, those participants with a strong interest in research, such as Andrew, Catherine, and Danielle, were already pursuing careers that enabled them to do research. In some cases, such as that of Andrew, they wished to change research area; however, the desire to simply do research of some sort was already something they could satisfy without returning to school.

\section{Desire to teach in higher education}

This motivation was the most common reason our participants cited for returning to school. Teaching typically does require an advanced degree; at some institutions, such as community colleges and smaller teaching-focused schools, it may be possible to teach with a masters' degree, but larger universities typically require a doctorate. Therefore, if a practicing engineer without a graduate degree decided that he or she wished to teach, they would be unable to satisfy this desire without returning to school.

\section{Desire to benefit others through this work}

Many of our participants were interested in the impact of their work and its societal benefit. Brenda spoke of how her research would affect others, and said that it was "really important stuff." Similarly, Catherine spoke of her desire to "to improve the planet earth." However, no one expressed that this was a motivation to return to graduate school. This is likely because, again, our participants were able to carry out important work outside of the graduate school setting, and were unlikely to feel that they could do more to benefit humanity as a graduate student than as a professional.

\section{Desire to advance in my current employment}

This motivation matches with the desire of three of our participants to advance in their current career pathway. While one of them chose to change his employer, he was planning to pursue the same type of specialty in his post-graduate employment, and therefore this category parallels our category of advancement in an existing career pathway. These participants did have to weigh the benefits of the graduate degree against time out of the workforce, however; the time spent on a graduate degree is time that they would be out of the active workforce at their employer, and this could result in missed opportunities there.

\section{Desire for a job that pays well}

None of our participants expressed the thought that they would improve their financial outlook by pursuing a graduate degree; in fact, they were generally concerned about the negative impact of graduate school on their finances. This is almost certainly because they all were able to earn competitive salaries at their jobs; while graduate school might increase their long-term earning potential, the short-term costs were high. As advancement in their current careers was a motivation for some participants, it is possible that higher pay due to that advancement was a factor; however, it was not expressly mentioned as a motivation. 
The lifestyle of a scientist

Our participants were already pursuing careers in engineering or science, and therefore there was no need for them to pursue a graduate degree in order to obtain this lifestyle.

The high regard in which scientists are held

As with the previous category, our participants already were engineers or scientists, and were respected as such.

\section{Desire to change careers}

While none of our participants wished to change careers, two of them did wish to change the focus of their career. This shift was a significant priority to them, and they felt that a graduate degree would facilitate it. In Anderson and Swazey's work, this was a relatively minor motivation for graduate school; this is entirely logical, considering that many of the students they surveyed were direct-pathway students who did not have an existing career to change. Logically, one would expect that in a population of returners, this would be more significant than in the general population of graduate students

\section{Couldn't think of anything better to do}

While this was the least significant motivation found by Anderson and Swazey, it was still a motivation for some students. However, in our population this did not appear, and in fact the very possibility of this motivation was emphatically rejected. As Brenda stated, "you're making sacrifices and you're not going to play around, this isn't... just something that you do because it's the next stage of life." Because of the large commitment of time and the financial impact, it is logical that returners would think through their goals very carefully before making major life changes and returning to school.

The returners in our study had a much smaller range of motivations than those seen in the general graduate school population of scientists and engineers. While our sample was relatively small with ten participants, in-depth analysis of the issues discussed by those participants suggests that some motivations will be intrinsically less likely to appear for returners. Because professionals in the workforce typically have multiple opportunities to gain knowledge, do research, benefit others, and enjoy the pay, lifestyle, and respect of a technical professional, they are less likely to see this as a motivation to return to graduate school. The various possible motivations for graduate school can all be seen as statements of the value of the graduate degree. In Eccles' work on Expectancy Value Theory, these could be characterized as utility value, attainment value, or interest value ${ }^{15}$. All of the motivations expressed in this study were related to utility; the motivation for obtaining a graduate degree was directly related to how it facilitated career goals that were important to the participant, as found in our previous work ${ }^{9}$. This also agrees with the findings of Stoecker, who found that physical therapists returning to school for a graduate degree were driven by vocational goals, rather than simply an interest in learning more about their field ${ }^{9}$. 


\section{Conclusion}

In this paper, we examined the reasons why professionals may choose to leave the workforce to return to graduate school. By better understanding these reasons, graduate schools will be better equipped to attract these returners and advise them as they pursue their goals.

\section{Bibliography}

${ }^{1}$ Hofinger, R. J. and Feldmann, L. J. (2001). "The Role of the Adult Student in the Classroom". American Society for Engineering Education Annual Conference \& Exposition, Albuquerque, NM.

${ }^{2}$ MacFadgen, L. (2008). "Mature Students in the Persistence Puzzle: An Exploration of the Factors that Contribute to Mature Students' Health, Learning, and Retention in Post-Secondary Education”, Canadian Council on Learning.

${ }^{3}$ Prusak, Z. (1999). "Learning Environment in Engineering Technology with a High Percentage of Non-Traditional Students". American Society of Engineering Education Annual Conference \& Exposition, Charlotte, NC.

${ }^{4}$ University of Michigan. (2011). [Graduate student population]. Unpublished raw data.

${ }^{5}$ Schilling, W. (2008). "Issues Effecting Doctoral Students Returning to Engineering Education Following Extensive Industrial Experience", American Society for Engineering Education Annual Conference \& Exposition, Pittsburgh, PA.

${ }^{6}$ Strutz, M. L., Cawthorne Jr., J.E., Ferguson, D. M, Carnes, M.T. \& Ohland, M.W. (2011). "Returning Students in Engineering Education: Making a Case for 'Experience Capital."” American Society of Engineering Education Annual Conference \& Exposition, Vancouver, BC.

${ }^{7}$ Peters, D. L. and Daly, S. R.(2011) "The Challenge of Returning: Transitioning from an Engineering Career to Graduate School”, American Society for Engineering Education Annual Conference \& Exposition, Vancouver, BC.

${ }^{8}$ Peters, D. L. and Daly, S. R. (2012) "Returning to Graduate School: Expectations of Success, Values of the Degree, and Managing the Costs". Journal of Engineering Education (submitted).

${ }^{9}$ Stoecker, J. L. (1991) "Factors Influencing the Decision to Return to Graduate School for Professional Students". Research in Higher Education 32(6), 689-701.

${ }^{10}$ Crede, E. and Borrego, M. J. (2011) "Undergraduate Engineering Student Perceptions of Graduate School and the Decision to Enroll”, American Society for Engineering Education Annual Conference \& Exposition, Vancouver, Canada

${ }^{11}$ Perna, L. W. (2004) "Understanding the Decision to Enroll in Graduate School: Sex and Racial/Ethnic Group Differences”, Journal of Higher Education, 75(5), 487-527.

${ }^{12}$ Anderson, M. S. and Swazey, J. P. (1998) "Reflections on the Graduate Student Experience: An Overview". New Directions for Higher Education, no. 101, 3-13.

${ }^{13}$ Fairweather, J. and Paulson, K. (1996). "Industrial Experience: Its Role in Faculty Commitment to Teaching", Journal of Engineering Education, no. 85, 209-215.

${ }^{14}$ Anderson-Rowland, M. (2008) "Thinking About Graduate School”, American Society for Engineering Education Annual Conference \& Exposition, Pittsburgh, PA.

${ }^{15}$ Eccles, J. S. (2009). "Who am I and what am I going to do with my life? Personal and collective identities as motivators of action". Educational Psychologist, 44(2), 78-89. 